\title{
Pendampingan Pembuatan Data Digital Manggis pada Kelompok Tani Bina Mandiri Dusun Nyiurbaye Gawah, Lombok Barat
}

\section{Encouraging Database Devepoment of Mangosteen Production Kelompok Tani Bina Mandiri Dusun Nyiurbaye Gawah, Lombok Barat}

\author{
Kurniawan Yuniarto ${ }^{1}$, Joko Sumarsono${ }^{1}$, Cahyo Mustiko Okta Muvianto², \\ Muhamad Ihsan Febriyanto Mbele ${ }^{1}$ \\ 1 Program Studi Teknik Pertanian, Fakultas Teknologi Pangan dan Agroindustri, Universitas Mataram, Jl. Majapahit No.62, \\ Gomong, Kecamatan Selaparang, Kota Mataram, Nusa Tenggara Barat 83115 \\ 2 Jurusan Teknik Elektro, Fakultas Teknik, Universitas Mataram, Jl. Majapahit No.62, Gomong, Kecamatan Selaparang, \\ Kota Mataram, Nusa Tenggara Barat 83115 \\ *Penulis Korespondensi: kurniawan2006@unram.ac.id \\ Diterima Oktober 2020/Disetujui Juni 2021
}

\begin{abstract}
ABSTRAK
Database digital komoditas pertanian sangat diperlukan di era revolusi 4.0 dan sosial 5.0. Pembuatan sistem informasi pertanian manggis di kelompok tani Bina Mandiri sangat vital untuk mendukung keberlanjutan aktivitas usaha tani dan administrasi ekspor di masa depan. Diseminasi ini dilakukan dengan kolaborasi bersama anggota kelompok tani Bina Mandiri, Dusun Nyiurbaye Gawah, Desa Batu Mekar, Kabupaten Lombok Barat. Tujuan kegiatan ini adalah pendampingan dalam digitasi pohon manggis dalam membuat peta digital distribusi manggis pada kelompok tani Bina Mandiri. Pelaksanaan kegiatan ini meliputi sosialisasi nilai pentingnya data digital, pengumpulan data primer, dan pembuatan sistem informasi pertanian manggis yang dapat terkoneksi dengan laman WebGIS. Hasil dari kegiatan ini adalah alih pengetahuan dan teknologi pemetaan manggis kepada kelompok tani Bina Mandiri. Selain itu, kelompok tani Bina Mandiri memiliki data digital terkait lahan dan pohon manggis sehingga dapat bermanfaat untuk keberlanjutan tata kelola dan pemanfaatan sisa ruang di lahan untuk penanaman pohon manggis dan pengetahuan akan kesalahan jarak tanam yang telah terjadi dalam praktik penanaman manggis.
\end{abstract}

Kata kunci: data, digital, era, manggis, WebGIS

\begin{abstract}
A digital database of agricultural commodities is indispensable in the 4.0 and social revolution eras of 5.0. The creation of a mangosteen agricultural information system at the Bina Mandiri farmer group is vital to support the sustainability of farming activities in preparation for future export administration. This dissemination was carried out in collaboration with members of the Bina Mandiri farmer group, Nyiurbaye Gawah hamlet, Batu Mekar village, West Lombok district. The purpose of this activity is assistance in digitizing mangosteen trees in making digital maps of mangosteen distribution in the Bina Mandiri farmer group. The implementation of this activity includes: socializing the importance of digital data, collecting primary data and creating a mangosteen agriculture information system that can be connected to a WebGIS page. The result of this activity is the transfer of knowledge and technology of mangosteen mapping to the Bina Mandiri farmer group. In addition, the Bina Mandiri farmer group has digital data related to land and mangosteen trees so that it can be useful for sustainable management and utilization of the remaining space on land for planting mangosteen trees and knowledge of spacing errors that have occurred in the practice of planting mangosteen.
\end{abstract}

Keywords: data, digital, era, mangosteen, WebGIS

\section{PENDAHULUAN}

Manggis merupakan salah satu komoditas buah-buahan ekspor utama di Indonesia nilai ekonomi yang cukup tinggi. Ekspor buah manggis memiliki peran besar dalam meningkatkan devisa negara dan pendapatan petani. Negara tujuan ekspor manggis antara lain Perancis, Belanda, Saudi Arabia, Jepang, Hongkong, Taiwan, dan Singapura (Narakusuma et al. 2013). Produsen buah manggis di Indonesia tersebar di 25 wilayah kabupaten sebagai penghasil untuk pasar ekspor maupun nasional. Kabupaten Lombok Barat termasuk dari salah satu kabupaten penghasil manggis dengan sentra produksi 
manggis di Kecamatan Lingsar. Hasil produksi buah manggis paling besar untuk wilayah Kecamatan Lingsar disuplai oleh kelompok tani dari Desa Batu Mekar. Manggis yang dihasilkan di Kecamatan Lingsar termasuk di dalamnya wilayah Batu Mekar sudah memiliki label manggis Lingsar. Keunikan yang dimiliki manggis varietas ini adalah memiliki rasa yang lebih manis dibandingkan dengan daerah lain. Hal ini erat kaitannya dengan agroklimat pertumbuhan manggis di wilayah Kecamatan Lingsar di kaki Gunung Rinjani. Selain itu, kemungkinan adanya keunikan pada zat tumbuh secara alami di areal perkebunan manggis.

Kelompok tani Bina Mandiri adalah salah satu pelaku pertanian buah-buahan di Kecamatan Lingsar dengan memiliki areal perkebunan seluas 11,83 ha yang terdiri atas tanaman buah manggis, rambutan, dan durian. Untungnya, buah manggis hasil panen kelompok sudah menjadi bagian pendukung untuk ekspor manggis dari Nusa Tenggara Barat. Tentunya, untuk meningkatkan nilai komoditas dari manggis kelompok tani Bina Mandiri perlu mengikuti aturan ekspor dengan baik. Saat ini tata kelola ekspor manggis yang dihasilkan oleh kelompok tani Bina Mandiri masih ikut dengan pihak ketiga karena ada beberapa dokumen yang belum terselesaikan. Aturan dalam prosedur ekspor mandiri cukup rumit secara administrasi yang mungkin agak susah dipenuhi oleh kelompok tani Bina Mandiri seperti aturan sertifikasi lahan. Data digitilalisasi secara geografis diperlukan untuk memenuhi aturan sertifikasi lahan. Pembangunan data digital dapat dilakukan dengan pemetaan untuk memperoleh data pertanian manggis yang terdiri atas data spasial dan atribut. Data spasial akan menampilkan letak atau posisi dari suatu objek geografis di permukaan bumi, sedangkan data atribut akan menjelaskan dari sebuah objek yang dapat berwujud informasi foto, numerik, narasi, dan lain sebagainya (Maulana et al. 2020).

Lebih lanjut, digitalisasi lahan milik kelompok tani dapat dipenuhi dengan cara membangun peta baik secara spasial dan atribut. Secara spasial akan diperoleh sebaran data ruang berupa luasan dan sebaran lahan. Selanjutnya, data atribut pohon manggis dapat dilakukan dengan cara pengukuran diameter pohon dan jarak tanam di dalam satu spasial lahan tumbuh yang berada di dalam kebun milik kelompok tani Bina Mandiri. Keberadaan data digital pertanian manggis di kelompok Bina Mandiri akan menjadi langkah awal dalam menunjang potensi ekspor manggis di masa depan.
Kumpulan data spasial dan atribut dapat diolah lanjut membentuk sistem informasi pertanian dengan basis sistem informasi geografis (SIG) kelompok tani manggis Bina Mandiri, Dusun Nyiur Gawah. Model pengolahan data pemetaan pertanian ini umum dilakukan dengan tujuan eksplorasi sumber daya pertanian yang sangat representatif. SIG memiliki kemampuan yang sangat baik dalam memvisualisasikan data spasial beserta atribut-atributnya (Puspitasari et al. 2018). SIG merupakan sistem informasi berbasis komputer yang merupakan penggabungan antara unsur peta (geografis) dan informasi tentang peta tersebut (data atribut), yang dirancang untuk mendapatkan, mengolah, memanipulasi, analisis, memperagakan, dan menampilkan data spasial untuk menyelesaikan perencanaan, mengolah, dan meneliti permasalahan. SIG pada dasarnya merupakan gabungan dari tiga unsur pokok, yaitu sistem, informasi, dan geografis (Manongga et al. 2010).

Selanjutnya, kumpulan data yang terolah dalam bahasa lunak ArcGIS akan diolah lebih lanjut melalui aplikasi WebGIS sehingga dapat di akses secara online. WebGIS merupakan gabungan antara rancangan grafis pemetaan, peta digital dengan analisis geografis, pemrograman komputer, dan sebuah database yang saling terhubung menjadi satu bagian web design dan web pemetaan (Suryamen \& Hsb 2017). Tujuan diseminasi ini adalah berupa pendampingan digitasi data manggis untuk menghasilkan peta digital distribusi dan sebaran pohon manggis di kelompok tani Bina Mandiri.

\section{METODE PELAKSANAAN KEGIATAN}

\section{Waktu dan Tempat}

Pelaksanaan pengabdian dari tanggal 8 Agustus-25 Oktober 2020 di kelompok tani Bina Mandiri bertempat di Dusun Nyiurbaye Gawah, Desa Batu Mekar, Kecamatan Lingsar, Kabupaten Lombok Barat, Provinsi Nusa Tenggara Barat, Indonesia

\section{Alat}

Peralatan yang digunakan dibagi menjadi dua, yaitu perangkat keras (hardware) dan perangkat lunak (software). Perangkat keras: GPS Garmin 60CSX dan Garmin 62S, sebagai pengambil titik koordinat di lapangan. Handphone sebagai media dokumentasi. Meteran $100 \mathrm{~m}$ sebagai alat ukur jarak dan diameter pohon. Buku sebagai media pencatatan data awal. Perangkat lunak terdiri 
atas excel, sebagai media pengolah dan digitasi data mentah, WinRAR sebagai alat kompresi data spasial dan data atribut, ArcMap sebagai media pembuatan peta dan atribut lahan, Google Earth Pro sebagai pengambilan citra satelit, dan ArcGIS Online untuk media penampilan peta di web.

\section{Tahapan Pelaksanaan Kegiatan}

Adapun metode yang digunakan pada kegiatan pengabdian ini terdiri atas 5 tahap, yaitu: 1) Sosialisasi kegiatan dan diskusi permasalahan dengan mitra Bina Mandiri; 2) Pengambilan data; 3) Digitasi dan pengolahan data; 4) Verifikasi data; dan 5) Sistem informasi geografis lahan pertanian di Dusun Nyiurbaye Gawah.

\section{- Sosialisasi kegiatan dan diskusi permasalahan dengan mitra Bina Mandiri}

Melakukan identifikasi masalah dengan mewawancarai kelompok tani Bina Mandiri. Berdasarkan hasil wawancara diperoleh informasi bahwa kelompok tani Bina Mandiri memiliki lahan kepemilikan sendiri untuk penanaman manggis namun tidak memiliki data jumlah pohon manggis, jumlah produksi maupun data digital lahan. Kelompok tani beranggotakan 23 petani akan mendampingi dalam pengumpulan data serta memberikan informasi data atribut yang diperlukan dalam penyusunan digitasi lahan manggis.

\section{- Pengambilan data}

Melakukan pengambilan data spasial dan nonspasial terkait pembuatan basis data dan SIG. Pengambilan data spasial menggunakan GPS untuk pengambilan titik-titik koordinat lahan di setiap petani manggis. Data spasial juga menggunakan program Google Earth Pro untuk pengambilan data citra satelit. Pengambilan data pendukung atau data non-spasial dilakukan secara primer, yaitu dengan wawancara kepada para petani dan pengukuran langsung di lapangan. Lembar kuesioner data spasial dan atribut yang digunakan terlihat pada Tabel 1.

\section{- Digitasi dan pengolahan data}

Melakukan pengolahan data menggunakan program excel sebagai media digitasi data pertanian dan program ArcMap sebagai media pembuatan peta beserta atribut-atribut pendukung sebagai dasar dari sistem WebGIS yang dibuat.

\section{- Verifikasi Data}

Melakukan verifikasi terhadap hasil peta pertanian yang telah dibuat kepada kelompok tani Bina Mandiri demi mengantisipasi kurang atau salahnya data-data yang ditampilkan di peta pertanian tersebut.

\section{- Sistem informasi geografis lahan pertanian di Dusun Nyiurbaye Gawah}

Menampilkan hasil pemetaan beserta atributatribut dalam sebuah WebGIS, dalam kegiatan pengabdian ini file yang diolah di dalam ArcGIS diubah ke dalam ArcGIS online dan menjadi informasi publik untuk dapat diakses secara online.

\section{HASIL DAN PEMBAHASAN}

\section{Forum Grup Diskusi}

Kelompok tani Bina Mandiri beranggotakan 23 orang petani termasuk pengurus kelompok (ketua, sekretaris, dan bendahara). Komoditas hasil kebun di kelompok tani Bina Mandiri adalah manggis, rambutan, dan durian. Luas lahan yang tercatat dari kelompok tani Bina Mandiri sekitar $118.254 \mathrm{~m}^{2}$ atau 11.83 ha. Kelompok tani Bina Mandiri memiliki pendamping, yaitu dua orang penyuluh lapangan dari UPTD Pertanian Kecamatan Lingsar untuk komoditas manggis, durian, dan rambutan. Berbagai perkembangan dan kendala yang dihadapi kelompok tani di Desa Batu Mekar termasuk di kelompok tani Bina Mandiri umumnya diketahui oleh kedua penyuluh tersebut.

Berdasarkan hasil diskusi dan pengalaman dalam bertani manggis di kelompok Bina Mandiri terdapat beberapa permasalahan seperti munculnya serangan larva daun. Hal ini muncul karena kurangnya tindakan pertanian yang baik yang dilakukan oleh para petani. Praktik bertani secara turun temurun belum menerapkan langkah-langkah pertanian yang benar dalam budi daya manggis seperti pemangkasan setelah masa panen selesai. Fungsi dari pemangkasan

Tabel 1 Lembar kuesioner data spasial dan atribut

\begin{tabular}{cccccc}
\hline Kode lahan & Nama pemilik & Batas titik lahan & Kode pohon & Diameter pohon & Jarak pohon \\
\hline xxxx & yуyyy & $\begin{array}{l}\text { Lattitude: } \mathrm{xxx} \\
\text { Longitude: } y y y\end{array}$ & XXXX & XXXX cm & XXX m \\
\hline
\end{tabular}


cabang dan ranting yang tidak produktif adalah merangsang pertumbuhan tunas produktif, meningkatkan penetrasi cahaya matahari ke dalam tajuk, memudahkan pemeliharaan, dan mengurangi serangan organisme pengganggu tanaman.

\section{Pengambilan Data Primer}

Tim pengabdian melakukan pengumpulan data-data lapangan meliputi data luasan dan atribut lahan. Petani Bina Mandiri dan tim pelaksana pengabdian turun ke lahan untuk mendapatkan titik-titik koordinat batas lahan yang terekam di dalam GPS dalam koordinat Universal Transverse Mercator (UTM) untuk setiap titiknya. Data spasial dalam kegiatan pengabdian ini berupa batas administrasi wilayah Dusun Nyiurbaye Gawah, batas lahan setiap petani anggota kelompok, dan titik-titik pohon manggis di lahan manggis anggota kelompok Bina Mandiri. Anggota kelompok tani pemilik lahan yang sedang dipetakan ikut serta mendampingi sehingga batas lahan yang direkam GPS benar atau sesuai, hal ini bertujuan untuk memverifikasi data yang dikumpulkan. Gambar 1 menunjukkan kegiatan pengambilan data di lapangan.

Selanjutnya, kumpulan data spasial yang berupa titik-titik koordinat yang terekam di dalam unit GPS di pindahkan ke komputer dengan dukungan software dNR. Data-data koordinat yang telah diunduh dilakukan pengolahan menggunakan software ArcMap untuk menjadi bahan-bahan data spasial dengan bentuk shapefile. Prosedur ini seperti yang disampaikan oleh peneliti lain di mana titik-titik koordinat akan diolah menjadi data shapefile, yaitu sebuah format data untuk menyimpan data spasial nontopologis berbasis vektor (Maulana et al. 2020).

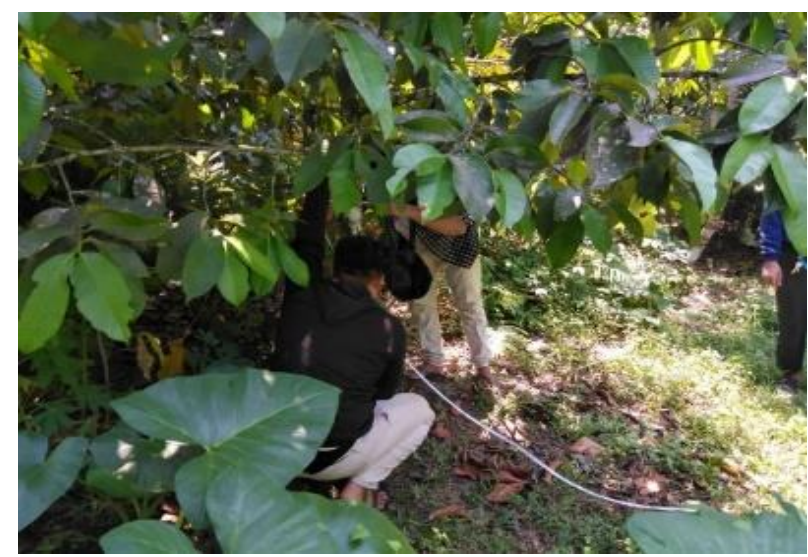

aa
Data yang telah berubah dalam bentuk data shapefile polygon yang terdiri atas informasi batas lahan manggis dan sebaran pohon manggis di dalam lahan. Sampai dengan tahap ini sudah diperoleh data spasial dasar yang mengungkapkan sebaran pohon manggis di dalam wilayah petakan lahan di kelompok tani Bina Mandiri, Dusun Nyiur Gawah. Selanjutnya, data kepemilikan lahan dibuat dalam bentuk petakpetak berdasarkan kepemilikan anggota kelompok tani Bina Mandiri seperti terlihat pada Gambar 2 dan 3.

Pembuatan petak-petak lahan dalam hasil pemetaan dilakukan dengan menghubungkan titik-titik koordinat atau node petakan petani lahan Manggis dengan menggunakan software ArcMap sehingga menjadi bentuk luasan atau polygon (Mufidah 2006). Sebagai contoh untuk menjelaskan Gambar 5, peta lahan milik Bapak Landuh Arman. Titik-titik koordinat lahan Bapak Landuh Arman diolah menjadi bentuk shapefile menggunakan menu editor. Titik-titik lahan tersebut dihubungkan membentuk petakan dua dimensi yang disebut polygon. Selanjutnya, shapefile polygon lahan manggis ini dapat dilakukan operasi perhitungan luas lahan tersebut sehingga didapatkan data atribut pertama untuk shapefile polygon tersebut. Pembuatan shapefile polygon dilakukan terhadap semua jenis data yang berbentuk dua dimensi dan memiliki luas, seperti luas Dusun Nyiurbaye Gawah.

Sebagai tambahan, data atribut untuk digitasi manggis pada kelompok Bina Mandiri diperoleh dengan melakukan wawancara dan pengukuran langsung atribut pohon manggis milik setiap anggota petani Bina Mandiri. Data-data atribut didefinisikan dalam bentuk parameter yang terdiri atas nama pemilik lahan, kode setiap pohon manggis, diameter pohon manggis,

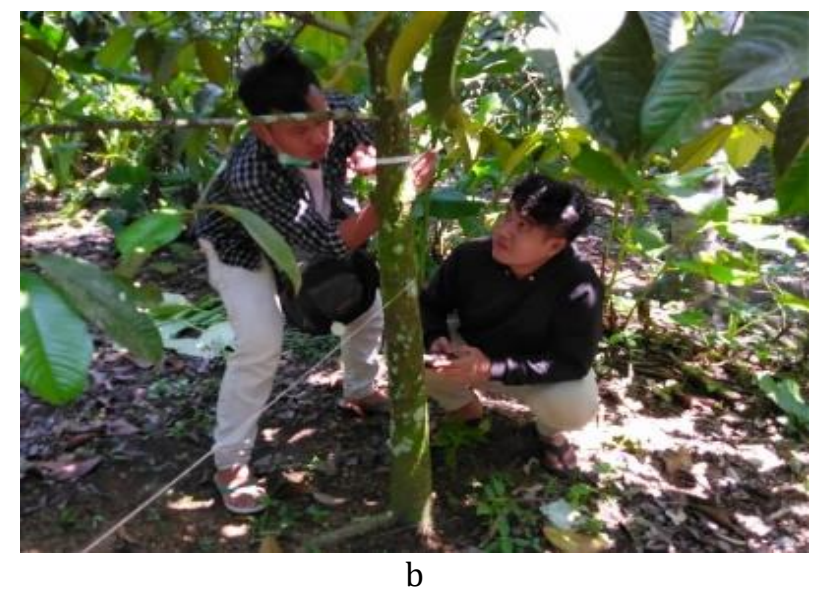

Gambar 1 a dan b Pengambilan data di lapangan. 


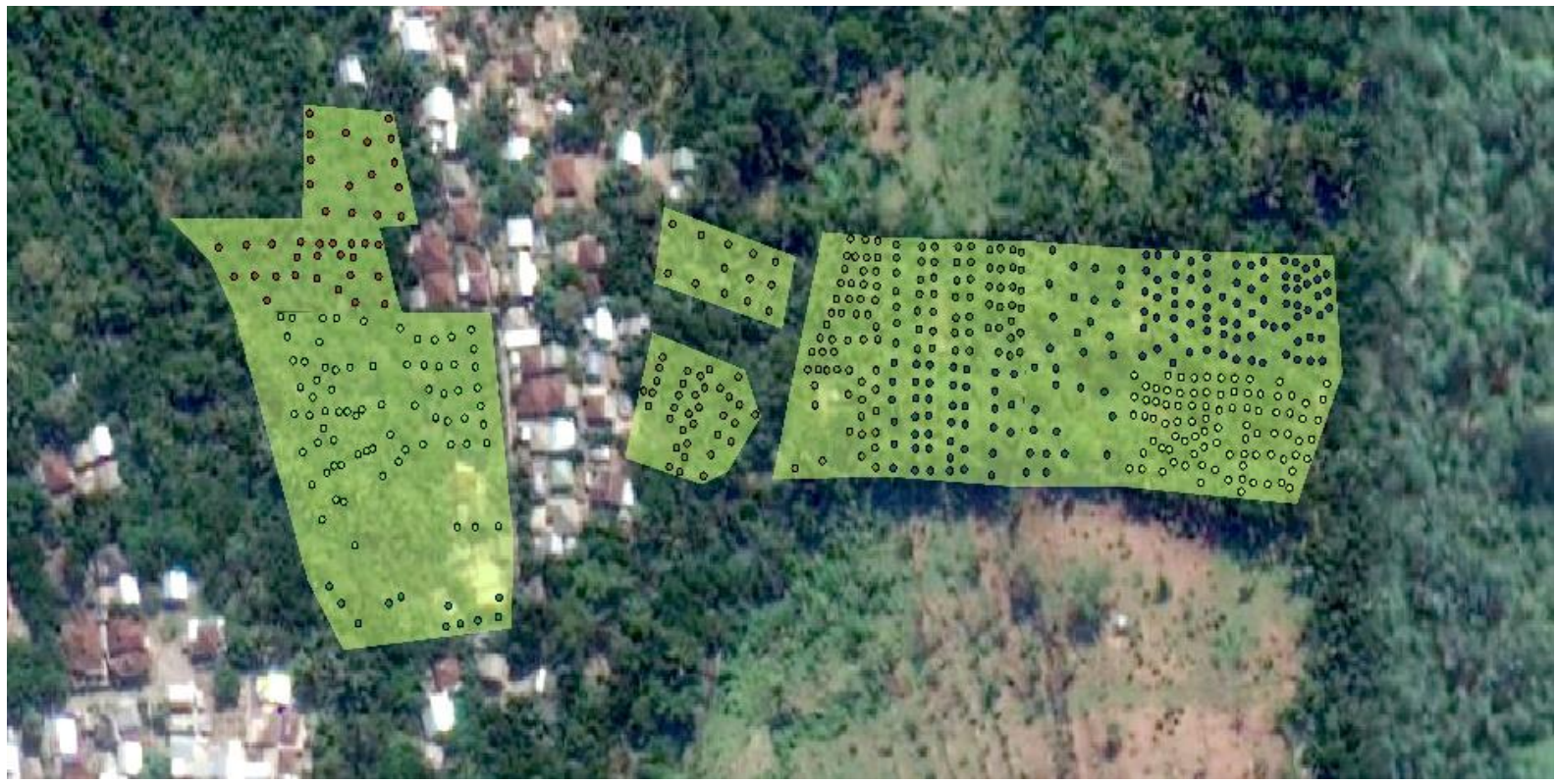

Gambar 2 Hasil pemetaan lahan dan titik pohon manggis Kelompok Bina Mandiri Dusun Nyiurbaye Gawah.

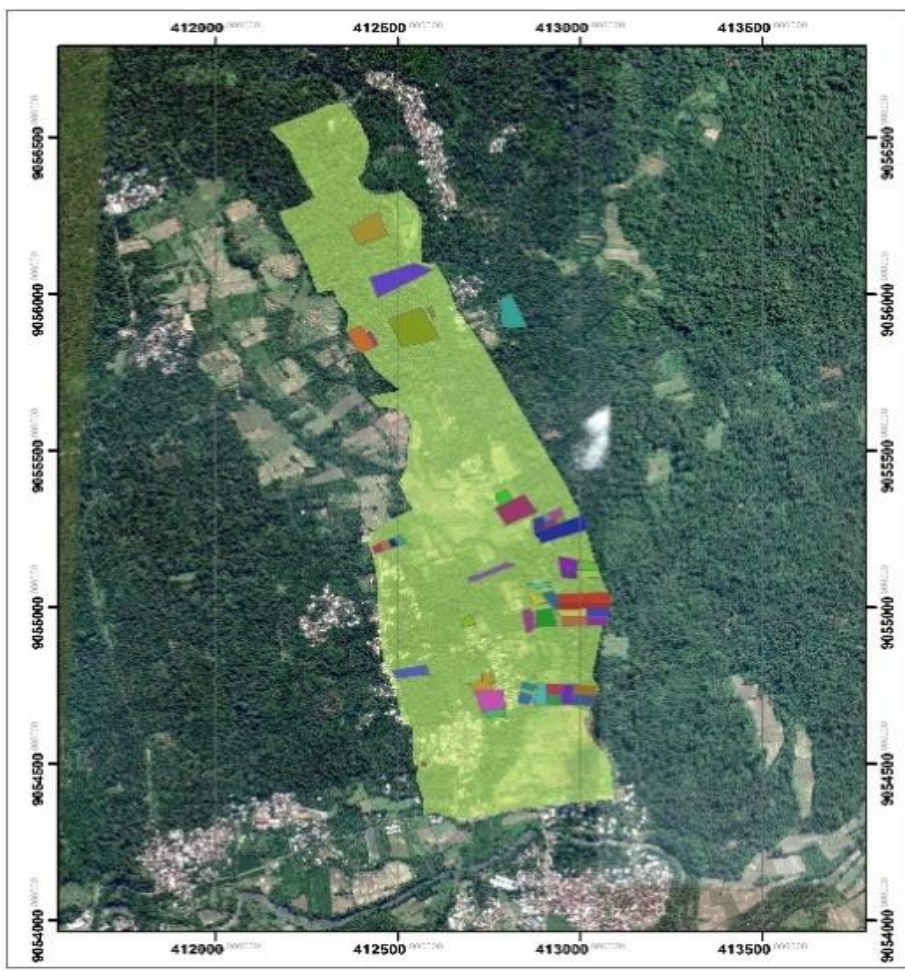
PETA LAHAN MANGGIS KELOMPOK BINA MANDIRI DUSUN NYURBAYE GAWAH
SKALA $\quad 1: 15000$
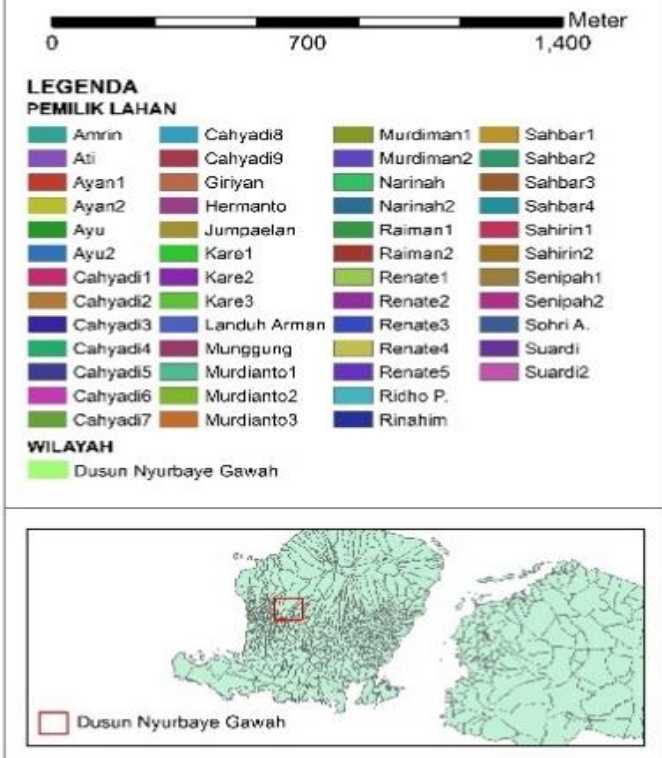

SUMBER DATA

BATASADAMNSISTRASI DESA NUSA TENGGARA BARAT TERBITAN DINAS
DUKG

Gambar 3 Peta kepemilikan lahan manggis anggota Kelompok Bina Mandiri di Dusun Nyiurbaye Gawah.

perkiraan jumlah produksi manggis per pohon, dan klasifikasi pohon manggis berdasarkan perkiraan jumlah produksi manggis. Data-data tersebut kemudian diolah dan dimasukan ke dalam setiap shapefile, baik titik ataupun polygon.

Shapefile pertama adalah shapefile Dusun Nyiurbaye Gawah. Shapefile ini mengandung informasi-informasi, yaitu keterangan nama dusun, luas dusun, nama kelompok, jumlah anggota kelompok, jumlah pohon manggis, dan perkiraan potensi produksi manggis. Shapefile ini merupakan shapefile paling dasar yang mengandung informasi umum terkait pendugaan potensi produksi manggis di Dusun Nyiurbaye Gawah. Shapefile dan atribut-atribut tersebut dapat dilihat pada Gambar 4.

Atribut di dalam Shapefile ini berisi tentang penjelasan nama-nama anggota kelompok Bina Mandiri, luas lahan manggis anggota tersebut, jumlah pohon yang diklasifikasikan berdasarkan besar diameter batang pohon, jumlah pohon, produksi manggis masing-masing pohon di setiap 


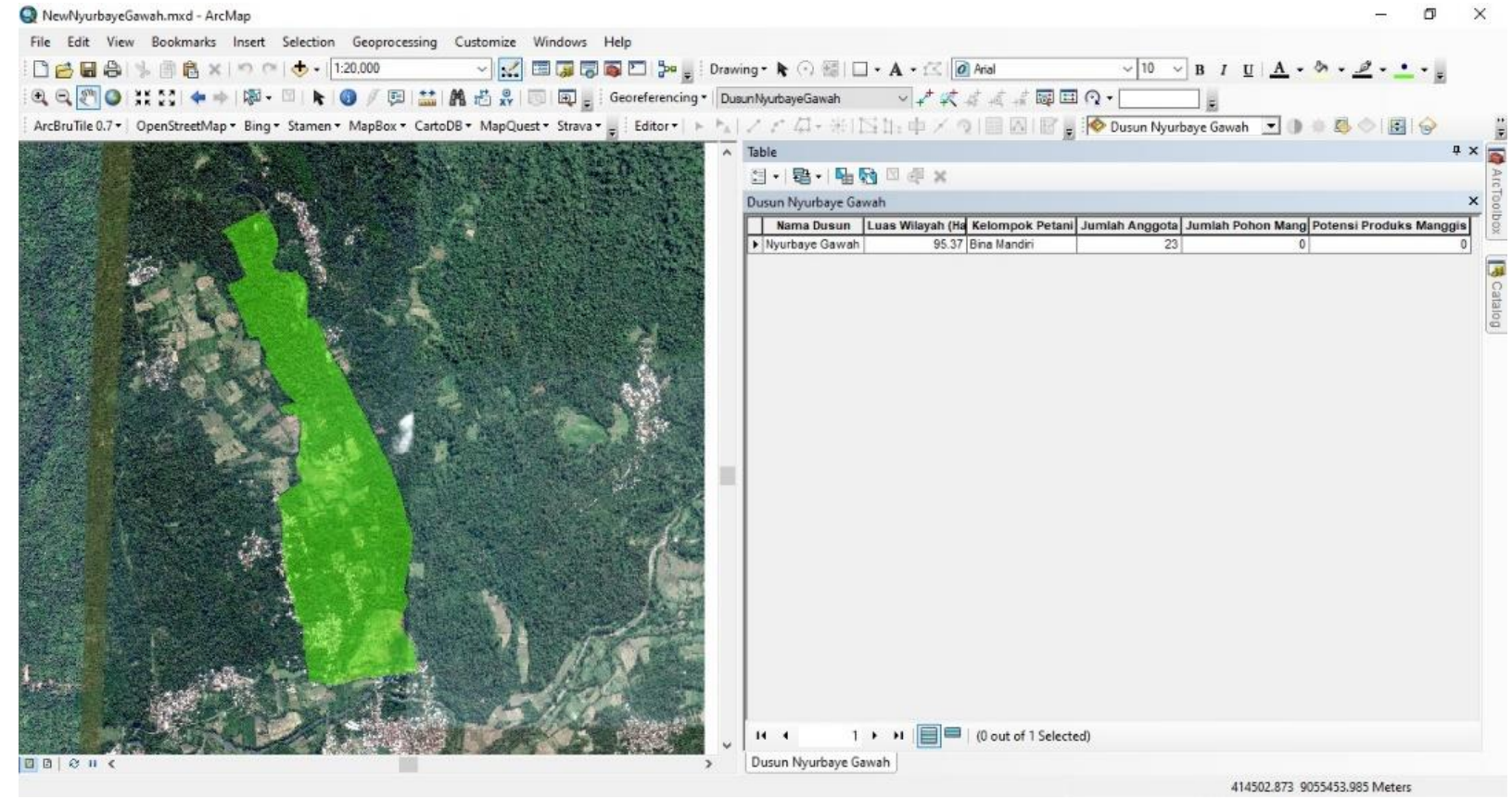

Gambar 4 Tampilan shapefile Dusun Nyiurbaye Gawah dan atribut di dalamnya.

lahan manggis berdasarkan klasifikasi, dan total produksi manggis pada lahan tersebut. Klasifikasi pohon manggis dilakukan dengan dasar wawancara kepada para petani anggota kelompok Bina Mandiri terhadap perkiraan produksi pohon-pohon manggis dengan berbagai ukuran diameter (Tabel 2).

Data-data atribut ini mampu memberikan informasi-informasi yang cukup untuk menjelaskan potensi produksi dan distribusi pohon manggis yang ada di Dusun Nyiurbaye Gawah. Atribut-atribut ini mampu memberikan penjelasan tentang perkiraan jumlah pohon dan produksi setiap petani anggota kelompok Bina Mandiri. Tidak hanya itu, dengan diketahui jumlah pohon dan diameter batang dari setiap pohon manggis, pendataan untuk kepentingan bantuan seperti bantuan pupuk dari dinas-dinas kepemerintahan kepada petani dapat dilakukan secara mudah, tepat sasaran, dan efisien.

\section{Sistem Informasi Pertanian dan WebGIS Manggis Kelompok Tani Bina Mandiri}

SIG berfungsi sebagai alat untuk menyimpan dan menampilkan data-data geospasial dan atribut kepada user atau pengguna. Pemanggilan informasi-informasi dapat dilakukan dengan menggunakan fitur yang ada di software ArcMap, yaitu identify. Penampilan informasi berupa tabel yang berisi data-data atribut yang telah dimasukkan ke dalam shapefile, baik berbentuk titik ataupun polygon. Pemanggilan data di dalam shapefile Dusun Nyiurbaye Gawah dapat dilihat pada Gambar 5.
Tabel 2 Data atribut klasifikasi pohon manggis berdasarkan diameter batang

\begin{tabular}{ccc}
\hline Diameter $(\mathrm{cm})$ & Kelas & Produksi $(\mathrm{kg})$ \\
\hline $0-20$ & $\mathrm{~A}$ & 0 \\
$21-26$ & $\mathrm{~B}$ & 6 \\
$27-30$ & $\mathrm{C}$ & 12 \\
$31-35$ & $\mathrm{D}$ & 24 \\
$36-40$ & $\mathrm{E}$ & 30 \\
$>40$ & $\mathrm{~F}$ & 50 \\
\hline
\end{tabular}

Pemanggilan data menggunakan basis software ArcMap memiliki kekurangan utama, yaitu tidak dapatnya diakses oleh khalayak umum. Hal ini dikarenakan data-data yang berada di dalam software ArcMap, baik data spasial dan data atribut, hanya bisa diolah dan dipanggil dengan aplikasi ArcMap atau sejenis (AutoCAD, ArcInfo, ERDAS, MapInfo, dan ILWIS) yang mampu menggunakan, menyimpan, dan mengolah data-data dengan format file shapefile (.shp) atau sejenisnya (Mufidah 2006). Tidak hanya kekurangan dalam akses oleh pengguna, proses memperbarui data yang ada di lapangan juga demikian. Proses memperbarui data hanya dapat dilakukan oleh user dengan menggunakan ArcMap dengan fitur editor dan melakukan proses editing secara manual di setiap shapefile lahan atau titik pohon

WebGis Manggis Kelompok Tani Bina Mandiri

ArcGIS online adalah platform teknologi yang kolaboratif dan berbasis cloud yang membantu pengguna dalam menciptakan, berbagi, dan mengakses peta, aplikasi, dan data 
(Nurrahmawati et al. 2019). Pengabdian ini menggunakan ArcGIS online dikarenakan fitur yang disediakan mudah dan praktis, baik dalam melakukan input data dan akses oleh client terhadap SIG yang telah dibuat sebelumnya.

Langkah pertama untuk launching secara online menggunakan fasilitas WebGis online adalah mempersiapkan data yang akan input ke dalam sistem ArcGIS online dengan cara mengumpulkan semua data shapefile yang telah berisi atribut-atribut ke dalam format archive (.zip) menggunakan dukungan software WinRAR. Data-data tersebut adalah shapefile Dusun Nyiurbaye Gawah, shapefile lahan manggis kelompok Bina Mandiri, dan semua shapefile titik pohon sebanyak 50 shapefile. Setelah data siap dan telah ditambahkan, dilakukan pengisian di kolom 'title' dan 'tag', user akan dibawa ke window baru (Gambar 6).
Kemudian pilih opsi 'open in map viewer' untuk melihat hasil pemetaan data-data spasial dan atribut yang telah ditambahkan. User akan dibawa ke window dimana user dapat melakukan proses editing peta yang akan ditampilkan kepada client. Setelah proses editing selesai, peta yang telah selesai disimpan melalui fitur save. Mengisi ulang kolom title, tags, dan summary sebagai informasi-informasi yang dapat dilihat dan diakses oleh client nantinya. Setelah dilakukan penyimpanan, maka peta telah disimpan di cloud server ArcGIS online dan dapat diakses oleh client.

Pengaksesan peta oleh client dapat dilakukan dengan link yang dapat dibuat. Pembuatan link dapat dilakukan dengan fitur share. Link yang dibuat dapat diakses melalui media komputer ataupun handphone (Gambar 7). Sehingga, peta dan data atribut dapat diakses oleh client sebagai

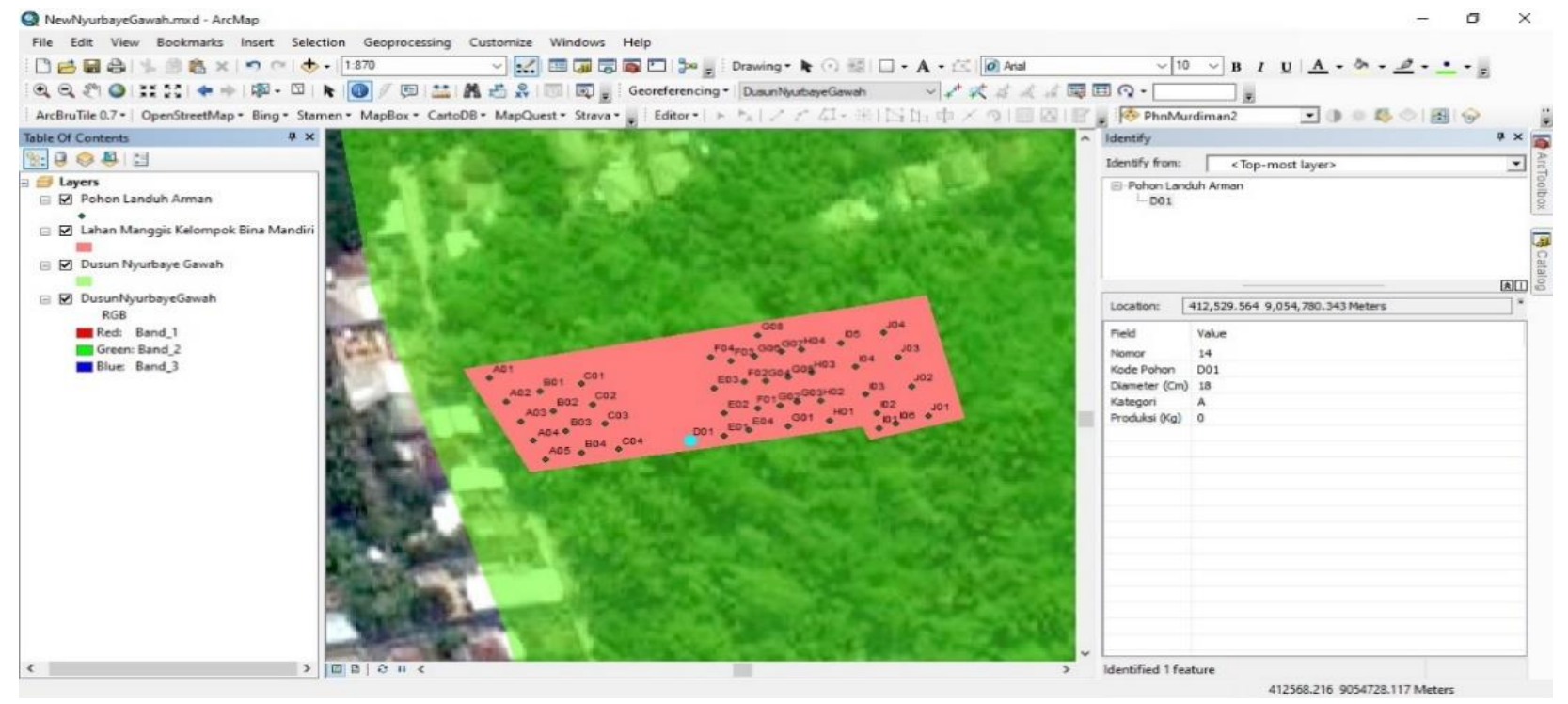

Gambar 5 Pemanggilan data di dalam shapefile titik pohon.

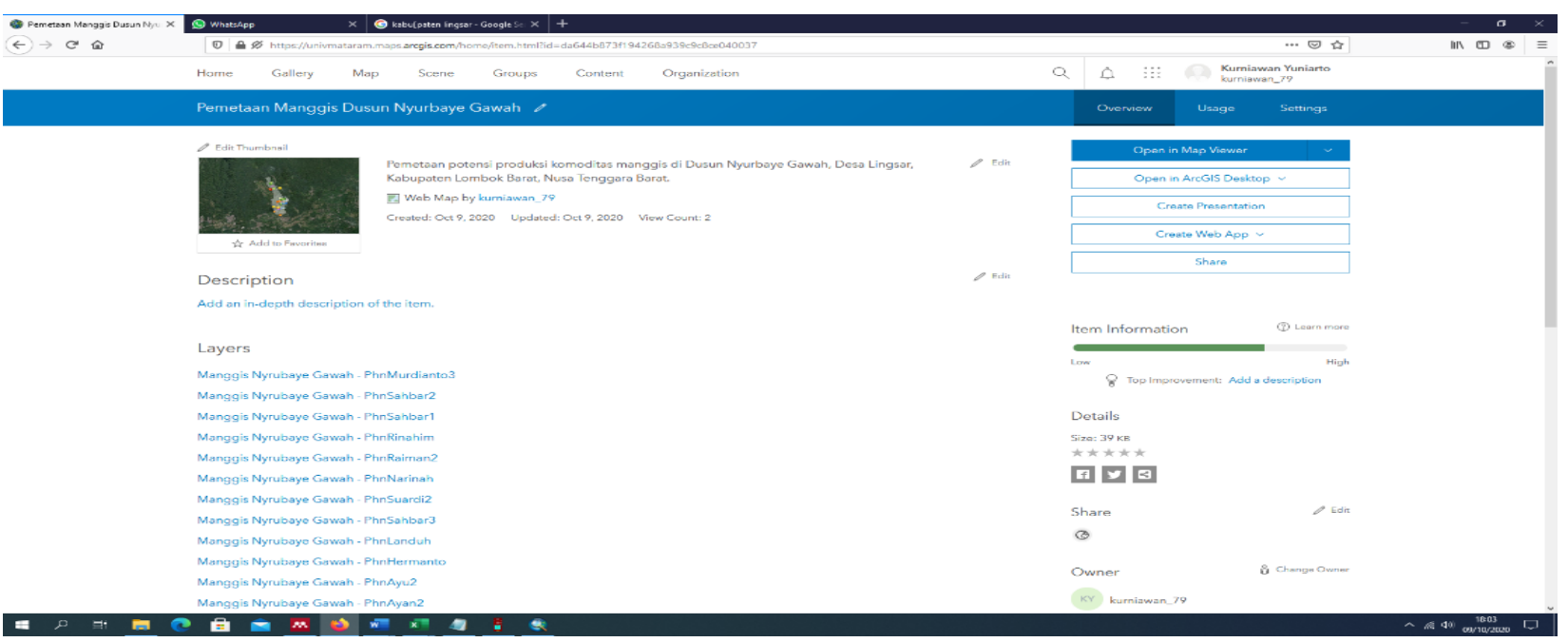

Gambar 6 Tampilan window setelah data di-input. 


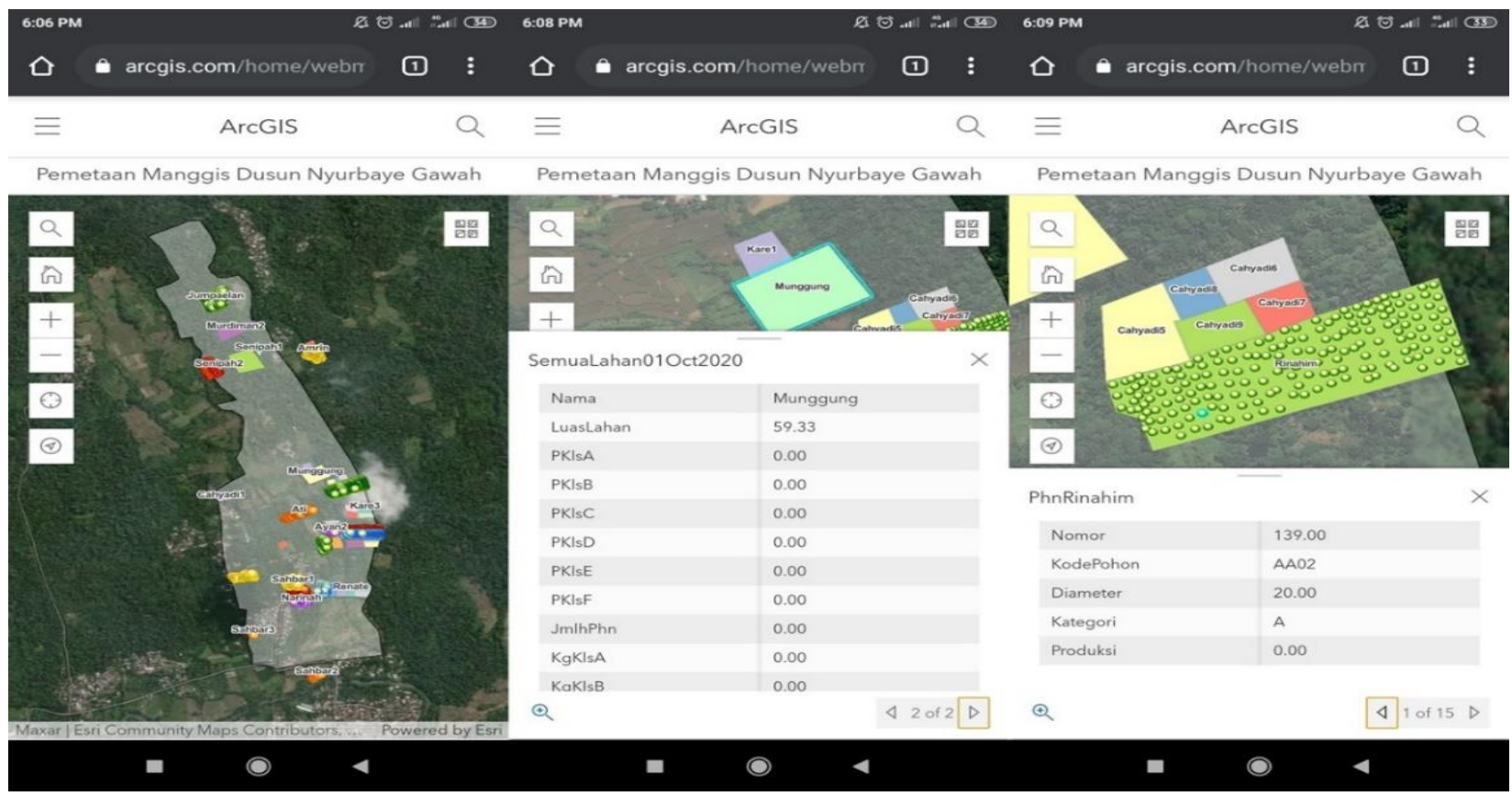

Gambar 7 Tampilan peta dan informasi atribut diakses dari handphone.

informasi persebaran tanaman manggis di lahan anggota kelompok Bina Mandiri di Dusun Nyiurbaye Gawah. Keuntungan ArcGIS online dalam penampilan data adalah sistem ini dapat diintegrasikan dengan aplikasi-aplikasi tambahan untuk memperkaya fitur yang diinginkan. Nurrahmawati et al. (2019) menggunakan aplikasi CarryMap sebagai pengganti media akses peta wisata dari handphone dikarenakan banyaknya fitur yang membantu kemudahan client. Tidak hanya itu, untuk memperkaya data dan visualisasi data ArcGIS online juga dapat diintegrasikan dengan Blogger dengan menggunakan bahasa pemrograman javascript, seperti yang dilakukan oleh Rohim et al. (2015). Hal-hal seperti inilah yang dapat dilakukan untuk menunjang kemudahan akses informasi data manggis di Dusun Nyiurbaye Gawah oleh client.

\section{SIMPULAN}

Fasilitas yang tersedia di software ArcGIS bermafaat dalam mendukung pembangunan basis data digital kebun manggis kelompok tani Bina Mandiri. Permasalahan dokumentasi lahan secara digital dapat diatasi dengan melakukan pengolahan dari kumpulan data spasial dan data atribut yang diambil langsung di lapangan lokasi penanaman kebun manggis di kelompok tani Bina Mandiri. Hasil kegiatan ini memberikan dampak untuk mempersiapkan pengembangan usaha tani pada kelompok tani Bina Mandiri dengan memiliki sistem informasi pertanian berbasis WebGIS. Hasil pembangunan digitasi data untuk kelompok Bina Mandiri telah disediakan di dalam akses WebGis online dengan laman https://www.arcgis.com/home/ webmap/viewer.html?webmap=9b1b67f31cb94 d50be612e9b8245ce98\&extent $=116.1912$,-

$8.5531,116.2229,-8.5349$.

\section{DAFTAR PUSTAKA}

Manongga D, Papilaya S, Pandie S. 2010. Sistem Informasi Geografis untuk Perjalanan Wisata di Kota Semarang. Jurnal Informatika. 10(1): 1-9. https://doi.org/10.9744/informatika. 10.1.1-9

Maulana F, Ardiansyah, Nizamuddin. 2020. Implementasi Katalog Unsur Geografis Indonesia (KUGI) pada Data Geospasial Provinsi Aceh. Jurnal Online Teknik Elektro. 1(1): 28-37.

Mufidah NMI. 2006. Pengantar GIS (Geographical Information System). Jakarta (ID): Penerbit Informatika.

Narakusuma MA, Fauzi AM, Firdaus M. 2013. Rantai Nilai Produk Olahan buah Manggis. Manajemen \& Agribisnis. 10(1): 11-21.

Nurrahmawati, Nugraha AL, Firdaus HS. 2019. Visualisasi Peta Wisata dan Fasilitas Penunjang di Kabupaten Temanggung Menggunakan Aplikasi Carrymap dan ArcGIS Online (Studi Kasus: Posong, Pikatan Water 
Park, Taman Kartini Kowangan). Jurnal Geodesi Undip. 8(1): 113-122.

Puspitasari SR, Awaluddin M, Firdaus HS. 2018. Pembuatan Aplikasi WebGIS Untuk Informasi Persebaran Sarana Dan Fasilitas Kesehatan di Kabupaten Kudus. Jurnal Geodesi Undip. 7(3): 1-10.

Rohim NW, Awaluddin M, Suprayogi A. 2015. Semarang Charity Map, Penyajian Peta Donasi Sosial Kota Semarang Berbasis Blogger
Javascript. Jurnal Geodesi Undip. 4(2): 117130.

Suryamen H, Habibi H. 2017. Pembangunan Sistem Informasi Komoditi Berbasis WebGIS untuk Pertanian, Perkebunan, dan Kehutanan Daerah Tanjung Raya Maninjau. Seminar Nasional Sains dan Teknologi. November. Sumatra Barat (ID). Hal: 1-7. 